\title{
Research on Communication Network Configuration and Simulation of Smart Substation Based on Ethernet
}

\author{
Jingxia Liu, Xuerang Zhang, Fuquan Zhang \\ College of Information Engineering, Inner Mongolia University of Science \& Technology, Baotou, China \\ Email: 1019455263@qq.com
}

How to cite this paper: Liu, J.X., Zhang, X.R. and Zhang, F.Q. (2020) Research on Communication Network Configuration and Simulation of Smart Substation Based on Ethernet. Energy and Power Engineering, 12, 14-24.

https://doi.org/10.4236/epe.2020.124B002

Received: January 3, 2020

Accepted: April 7, 2020

Published: April 10, 2020

\begin{abstract}
The characters of the intelligent substation communication network structure are analyzed in the paper. Combining existing integrated automation substation hardware circuit and VLAN (Virtual Local Area Network) research foundation to optimize the network configuration. In accordance with IEC61850 standard, the network is partitioned into several VLANs based on the Tag VLAN division method of ID address. Real-time communication packets between GOOSE networks, SV (sampling information) networks, and switches use 802.1Q protocol headers to distinguish these packets. Finally, OPNET simulation software was used to simulate and verify the simplified dual-star topology. The results demonstrate that the delay and traffic bandwidth meet the requirements of actual substation operation standards. Compared with ordinary single-star networks, the reliability is greatly improved and the effectiveness is improved.
\end{abstract}

\section{Keywords}

Intelligent Substation, Network Configuration, VLAN Division, GOOSE and SV, OPNET

\section{Introduction}

Integrated automation substation monitoring system develops very fast since 1980s. With the development of network, communication and industrial automation technologies, the automatic integrated monitoring system of the substation steps toward the dispersed and structured network. The bus-network with high delay was mostly adopted in the early stage of the monitoring system of the substation. Later, the Ethernet technology was introduced. Ethernet has been the 
decisive technology to the integrated development of the monitoring system of the substation. The intelligent electronic devices (IED) in different positions are integrated into the network, which consequently consists of the communication network with complete functions and high performances [1] [2] [3].

In this paper, based on the communication network of the monitoring system of the substation, the network structure of the substation of $220 \mathrm{kV}$ is analyzed. The functions of different parts are allocated in accordance with the space between three layers of the substation, and the network is built using double-star topology. The communication scheme that integrates GOOSE, SV and MMS and realizes transmission with the same port is adopted, which contributes to the diversity of the network construction. In Ethernet, the network is designed with the embedded Ethernet technology. VLAN division technology based on ID is used in the Ethernet of the substation to ensure the stable data exchange during transmission. Finally, a model is built based on OPNET network simulation software, to make the stability simulation analysis to the star network of the substation, consequently verifying the feasibility of double star network.

\section{Optimization of the Integration of GOOSE and SV}

The integration of GOOSE and SV networks is mainly used in bay level and process level network. The integration scheme of three networks based on the process level of the $220 \mathrm{kV}$ smart substation is introduced in the paper, which is mainly divided into the interval network excluding GSU transformer on the 220 $\mathrm{kV}$ high voltage side, the interval network of the $110 \mathrm{kV}$ external transformer and $35 \mathrm{kV}$ GOOSE and SV network. The configuration of the relay system of the smart substation is illustrated in details [4] [5].

Units in each interval configuration are merged, to collect the analog and switch signals and synchronize the signals like voltage and current. The measured data are output based on IEC 61850 Standard for the secondary equipment. Switching circuit and position signal acquisition circuit of the breaker and interval switch are completed at the intelligent terminal. The station is divided into station level, bay level and process level. The holistic network consists of two layers of double star network architecture, to ensure the shortest and fastest data transfer path and realize the simple control.

GOOSE, SV and MMS are integrated. GOOSE network Switch and SV network transmit with the same port, transferring two types of message data simultaneously. Double configurations of the $22 \mathrm{kV}$ relay protection equipment are connected into GOOSE A network and GOOSE B network, respectively [6] [7]. All measurement and control units are connected into GOOSE A. The interlocking information between the measurements equipment are transferred in the form of GOOSE message via MMS network. The connections between GOOSE and SV network and the smart equipment are shown in Figure 1. The VLAN division of regular substation is divided based on the port, which easily results in the net jam. The Tag VLAN division method based on VID discussed in the 


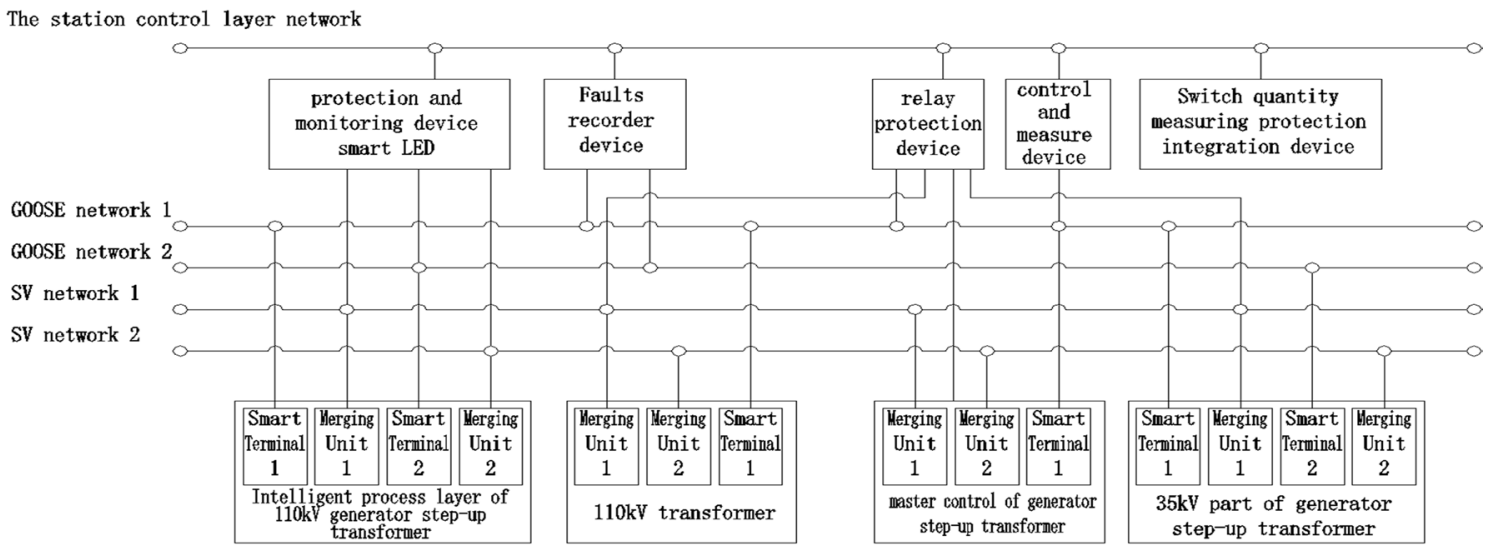

$110 \mathrm{kV}$ part

secondary equipment part of generator step-up transformer

Figure 1. Double-layer network configuration of GOOSE and SV.

paper can easily determine the priority of VLAN, which ensure the transmission order of the message and consequently reduces the load pressure of the Switch.

\section{Feasibility Analysis to the Switch Flow of the Smart Substation}

The Switch plays a vital important role in the communication network of the intelligent substation. In the network construction scheme proposed in the paper, GOOSE and SV transmit with the same port, which has requirement to the traffic carrying capacity of the Switch. The transmitted data are mostly one-way traffic and small amount of GOOSE and MMS message through the Switch. Suppose, there are 12 analog channels in each merging unit. The traffic flow output per second is shown in Equation (1).

$$
s=159 B * f_{a} * 80 * f p s / f
$$

where $B$ represents Bytes, taking 1024b; $f$ represents cycle, taking $5 s ; f_{a}$ represents unit cycle per second, taking 50; and fps represents message frames, taking 46b. Therefore, $s=5.088 M b i t / s$.

The traffic from distribution automation to each terminal in SV network is calculated in following formula.

$$
S_{n}=\sum_{i e N_{T}} N_{p-i} n f_{i}
$$

where, $N_{p-i}$ represents the number of the terminals; $f_{i}$ represents the number of traffic at $110 \mathrm{KV}$ terminal; and $N_{T}$ represents the type of the line terminal.

In the process level, signals between the Switches are received via GOOSE network. Suppose, the signal input of GOOSE network of the smart substation is $V_{j}^{1}=\left(V_{j 1}^{1}, V_{j 2}^{1}, \ldots, V_{j n}^{1}\right)$, where $n=1,2,3, \ldots$. . Initial unit $Z_{j}^{1}=\left(z_{j 1}^{1}, z_{j 2}^{1}, \ldots, z_{j m}^{1}\right)$, where $m=1,2,3, \ldots$. In the equivalent time-invariant system, the maximum delay time is used in iteration. In Node communication of the smart substation, the optimal power sent to the Switch from the merging unit and the intelligent IEC is: 


$$
S(t)=\operatorname{Re}\left(s_{t}(t) e^{j 2 \pi f_{c} t}\right)
$$

where, $f_{c}$ is the modulated transmission frequency of the GOOSE message.

In GOOSE and SV communication based on the IEC 61850 standard, the bandwidth flow of the intelligent IEC in one second is $S_{a}=0.006 \mathrm{Mbit} / \mathrm{s}$.

It can be seen that when the holistic network is in operation, the GOOSE message traffic and the merging unit SV message traffic has small influence on the bandwidth of the network. Therefore, the Switch can carry the transmission with the same port. All equipment can be connected into the network with the megabits interface.

\section{Interval Network Configuration Based on VLAN ID}

\subsection{The Switch Terminal Setting Analysis}

VLAN division can identify the useful and useless information and restrict the entry of useless information into the Switch [8]. The message transmission in the Switch is labeled TAG, which is the important mechanism to identify the message. PVID (Port VLAN ID) in VLAN port corresponds to the TAG of the message. When accessing the terminal, the message is compared to the VLAND ID in the TAG to identify whether it is permitted to pass through. PVID can record many VLAN ID. But there is only one PVID in one access port. When the IP message enters into the port of the Switch, the TAG information will be automatically produced on the message even if there is no TAG on the message but the port is equipped with PVID. If there is TAG on the IP message that has entered into the port of the Switch, the Ethernet Controller will identify the header. TAG VLAN is based on the IEEE802.1 Q Standard. The IEEE802.1 Q Standard has defined a new type of frame format. It adds a tag header after the source address of the standard Ethernet Frame, shown in Figure 3. When data frame passes through the Switch, the Switch will identify the VLAN that they belong to base on the VID information of the TAG and then transfer the data frame in the logic VLAN based on the rule.

\subsection{Network Configuration}

The GOOSE retransmission scheme defined by IEC 61850-7-2 guarantees the real-time and reliability of the message transfer. A kind of mapping of the communication service is used to classify the message level. There is one steady-state retransmission delay and three fault mutation delays in message transmission. When substation operates steadily, the steady-state retransmission delay lasts 3 $5 \mathrm{~ms}$ and the fault mutation delay is of the scale of millisecond, increasing successively. Figure 2 is the delay scheme of the mechanism.

Operation capacity of the Switch in $220 \mathrm{kV}$ substation in this paper is huge and the line is complicated. In debugging each intelligent IED and its corresponding MAC address of the GOOSE network, the MAC address should be changed if the line should be adjusted. Meanwhile, a group of wavetable should 


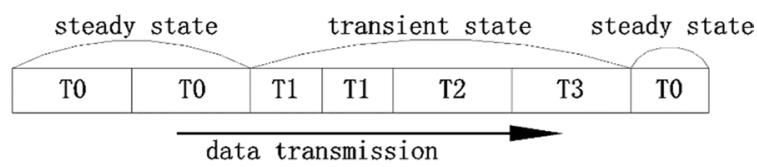

Figure 2. Transmission time of GOOSE service.

be changed in the Switch configuration manually. The operation is complicated. Due to its poor activity, it is not suitable used in the communication based on the port of the Switch in the large substation.

With the development of VLAN technology, VLAN division from the broad sense in the Switch of the two-layer three network integration discussed in the paper can be realized, reducing the traffic load of the network. Similar to the Switch, in engineering networking of GOOSE network, it is suitable for VLAN division based on VLAN ID. Many virtual work units are created in VLAN. Network topology relationship between intelligent IED is distributed to corresponding VLAN work unit via GOOSE network, avoiding to configuring the intelligent IED individually during the test.

In networking of GOOSE, the mutual information of GOOSE networking of $220 \mathrm{kV}$ smart substation is classified into two types, i.e., IED in guard space and IED between bus interval and other interval.

1) In guard space GOOSE networking, the type of each equipment and the type of receiving information include transformer protection receiving failure leading to trip GSU three sides, blocking reclosing of the receiving line of the line protection and the opposite side of the line remote tripping, input of the intelligent terminal of the receiver of GSU control device and transmission of GOOSE, receiving transformer in the space intelligent terminal and operation fault control signal, etc.

2) Main information types of GOOSE networking in IEB between the Bus and other spaces include Bus protection receiving its start failure signal, the bus connection interval control receiving the input of the intelligent terminal in its space and the transmission of GOOSE, the Bus intelligent unit responsible for receiving the control and remote control operation signals of the Bus.

According to the flow of above mentioned type of message and GOOSE message, GOOSE network can be configured to and VLAN can be divided in the IED of each voltage level in the interval. Taking VLAN division in GOOSE network of the $220 \mathrm{KV}$ intelligent substation taking No.1 switch as the backbone switch an example, the configuration scheme is shown in Table 1.

\subsection{United Transmission Mechanism of GOOSE Network and SV Network}

When Tag VLAN division is used in the transmission of GOOSE network and SV network with the same port, three logic requirements should be considered: 1) the equipment cannot send two different messages simultaneously and there is some delay during the transmission of GOOSE message; 2) When the port of the switch transmits the message, it could lead to the delay of another message; 
3) In dividing different VLAN, the messages have different priorities. To analyze the "dispersed degree" of the delay of the message in the whole process, to establish the priority rules of the message, the mean square deviation of the message delay is used to represent delay variation. It is defined as:

$$
T_{j}=\sqrt{\sum_{i=1}^{n}\left(T_{i}-T_{E T E}\right)^{2} / n}
$$

where, $T_{i}$ and $T_{E T E}$ represent the end-to-end delay and average end-to-end delay of No.i message, respectively, and $\mathrm{n}$ stands for the total number of messages passing through the switch and the network.

In the $220 \mathrm{kV}$ substation, the priority of the message is classified into the regular GOOSE message, interlocking GOOSE message, tripping GOOSE message and SV message, with the priority increased in the sequence, to protect the signal. To guarantee the steady and reliable transmission of the tripping message, the GOOSE message is transmitted continuously at the frequency of $0 / 1 / 2 / 4 \mathrm{~ms}$.

The setting of the priority of the message is listed in Table 2 .

The transmission between the merging unit and intelligent terminal with the

Table 1. Address configuration of the $220 \mathrm{kV}$ branch device.

\begin{tabular}{|c|c|}
\hline VID & Equipment included in VLAN \\
\hline 2 & Station control equipment and server \\
\hline $10-60$ & $\begin{array}{l}\text { mu in each interval of } 220 \mathrm{kv} \text { incoming line and } 66 \mathrm{kv} \text { feeder line, protection } \\
\text { control IEC, intelligent terminal }\end{array}$ \\
\hline $70-71$ & $\begin{array}{l}\text { mu in each interval of } 220 \mathrm{kv} \text { bus line and } 66 \mathrm{kv} \text { bus line, protection control IEC, } \\
\text { intelligent terminal }\end{array}$ \\
\hline $80-90$ & mu of interval 2 or interval 2 of the transformer, protection control IEC \\
\hline $210-290$ & $\begin{array}{l}\text { Station control equipment \& server and protection control IEC of each interval and } \\
\text { intelligent terminal }\end{array}$ \\
\hline $7010-7020$ & $\begin{array}{l}\text { mu of } 220 \mathrm{KV} \text { bus line interval, protection control IED, intelligent terminal and } \\
\text { protection control IEC of each interval and intelligent terminal on the } 220 \mathrm{KV} \text { side }\end{array}$ \\
\hline $7130-7160$ & $\begin{array}{l}\text { mu of } 66 \mathrm{KV} \text { bus line interval, protection control IED, intelligent terminal and } \\
\text { protection control IEC of each interval and intelligent terminal on the } 66 \mathrm{KV} \text { side }\end{array}$ \\
\hline
\end{tabular}

Table 2. Priority treatment of the real-time message in the process level network.

\begin{tabular}{cccccc}
\hline Message type & $\begin{array}{c}\text { Transmission } \\
\text { direction of the } \\
\text { message }\end{array}$ & $\begin{array}{c}\text { Transmission } \\
\text { mode }\end{array}$ & $\begin{array}{c}\text { Priority } \\
\text { level }\end{array}$ & $\begin{array}{c}\text { Delay } \\
\text { requirement } \\
\text { (ms) }\end{array}$ & $\begin{array}{c}\text { Transmission } \\
\text { frequency (HZ) }\end{array}$ \\
\hline SV message & From MU to IEC & Periodicity & 4 & 3 & 1200 \\
$\begin{array}{c}\text { GOOSE input } \\
\text { message }\end{array}$ & $\begin{array}{c}\text { From the intelligent } \\
\text { switch cabinet to IED }\end{array}$ & Periodicity & 1 & 3 & $\begin{array}{c}\text { Continuous } \\
\text { transmission with } \\
\text { the changing } \\
\text { interval }\end{array}$ \\
$\begin{array}{c}\text { GOOSE output } \\
\text { message }\end{array}$ & $\begin{array}{c}\text { From IED to the } \\
\text { intelligent switch } \\
\text { cabinet MU }\end{array}$ & Suddennes & 4 & 3 & $\begin{array}{c}\text { Triggered timing } \\
\text { transmission }\end{array}$ \\
\hline
\end{tabular}


same port means the packet transmission of GOOSE message and SV message. Today, the intelligent equipment can completely meet the requirement of the traffic bandwidth for the real-time transmission of GOOSE message and SV message. However, due to the transmission with equal interval of SV message, priority of the message should be set to ensure the real-time capability of the transmission, which consequently results in the negligible delay about $20 \mu \mathrm{s}$ of the message. Due to the heavy traffic of SV network, it is not suitable to divide SV and GOOSE into one VLAN. In sample value transmission of SV, IEC 61850-02 protocol communication agreement is strictly followed. Message transmission in main protection is simple, therefore, direct SV and tripping mode is used. Considering the large amount of information on $110 \mathrm{KV}$ side, internet SV and tripping mode is adopted.

\section{Simulation analysis}

\subsection{Simulation Environment Setting and the Model}

The simulation has been realized using OPNET network simulation software to simplify the double star topology [9] [10] [11]. It mainly simulates the traffic load and message delay of the Switch. The model is shown in Figure 3. Environment parameters are set based on actual substation. Node flow of GOOSE network is set to be 256 Byte and the interval of normal transmission of GOOSE message is set to be $1 \mathrm{~s}$. Time triggered transmission is set to be the constant transmission at the interval of $0 / 1 / 2 / 4 \mathrm{~ms}$. Two simulation priorities are set as described in Table 3. The node in the model is from 0 to 4,8 and 12 , simulating the message transmission of GOOSE network. Switch-1 and Switch 2 stand for the Switch in double star topology, respectively. Switch-0 is the model of the central Switch. And the environment is set as follows. The bandwidth of network is set to be $0 / 1 / 2 / 4 \mathrm{~ms}$, simulation time is $60 \mathrm{~s}$ and the packet loss rate is $0 \%$.

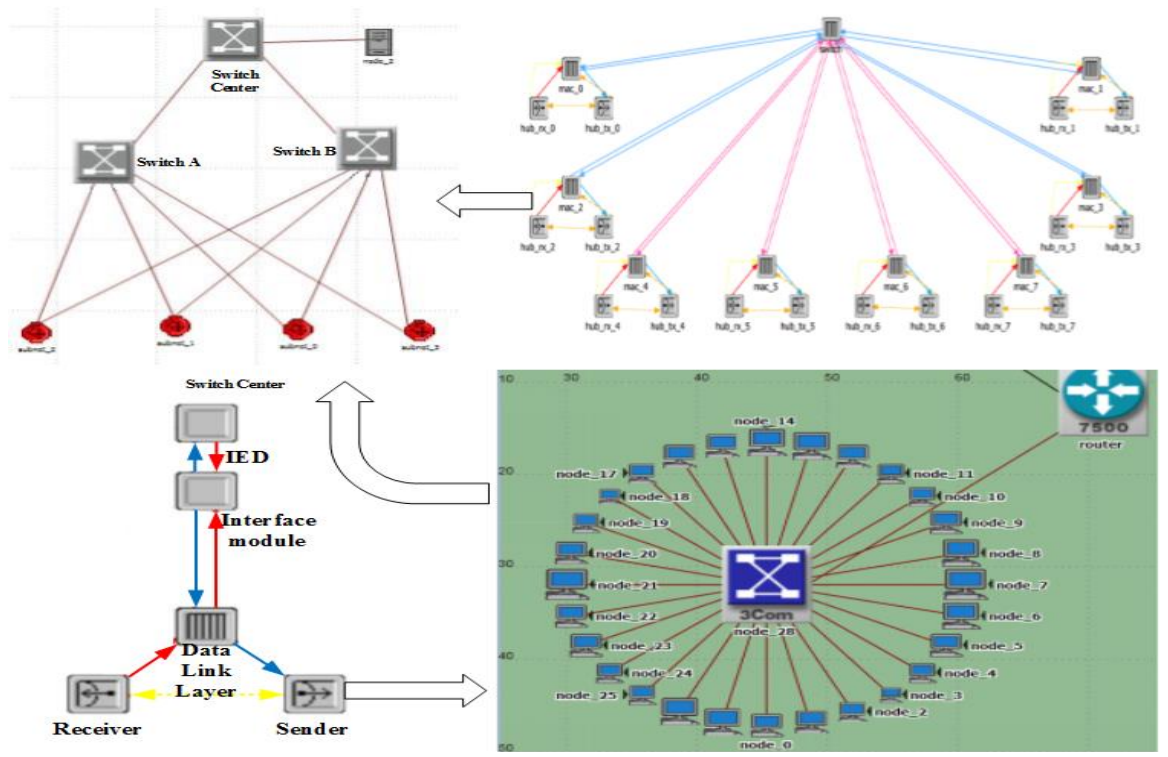

Figure 3. Double star simulation model of the substation. 


\subsection{Traffic Analysis When Substation Operation Runs Steadily}

It can be seen from the simulation diagram in Figure 4 that the average delay of point-to-point in SV subnet is about $110 \mu \mathrm{s}$. For the point-to-point data exchange, the data is processed by three IED equipment and one Switch. Therefore, the point-to-point delay of SV message is about $110 * 3+110=0.44 \mathrm{~ms}$. It shows that the delay of SV subnet of the process level of the substation meets the stipulation of the standard.

The traffic simulation results of the SV subnet are shown in Figure 5 and Figure 6, the flow between the Switch and the terminal is about $50 * 5.63=281.5 \mathrm{Mbps}$. There is not much difference between the flow from the terminal to the Switch and SV message, which indicates that GOOSE message has little impact on the forwarding volume of the Switch flow. Throughput between the Switch to the terminal is the unsuccessful delivery of data from the Switch to the terminal.

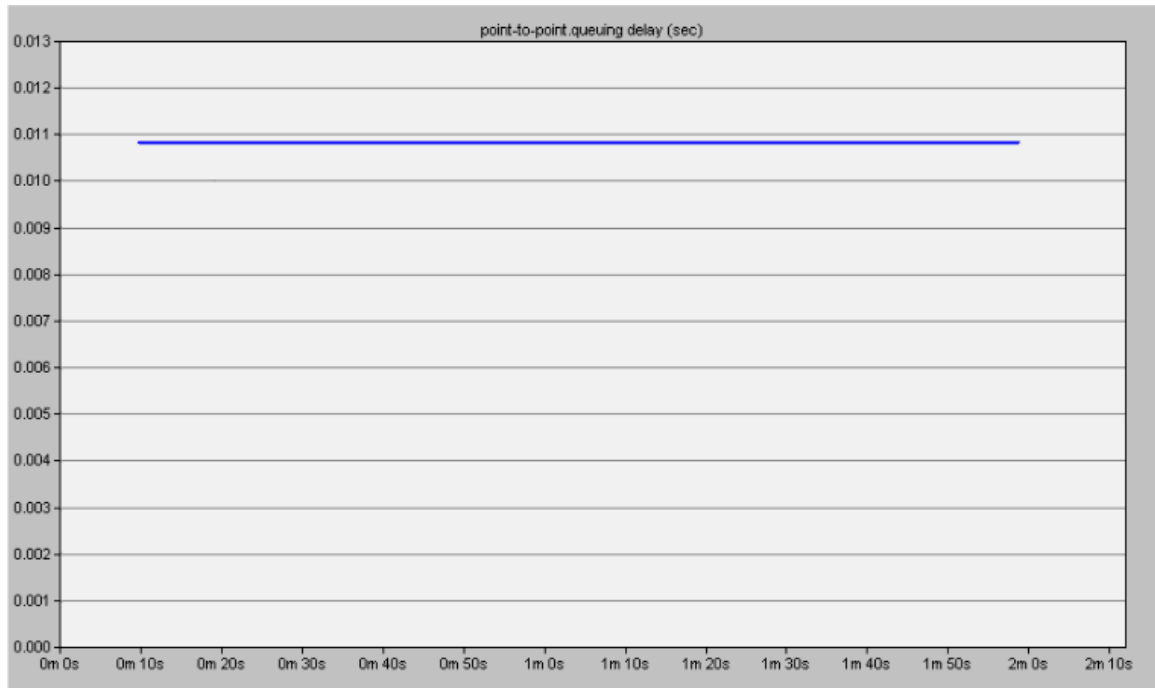

Figure 4. The average delay of SV subnet

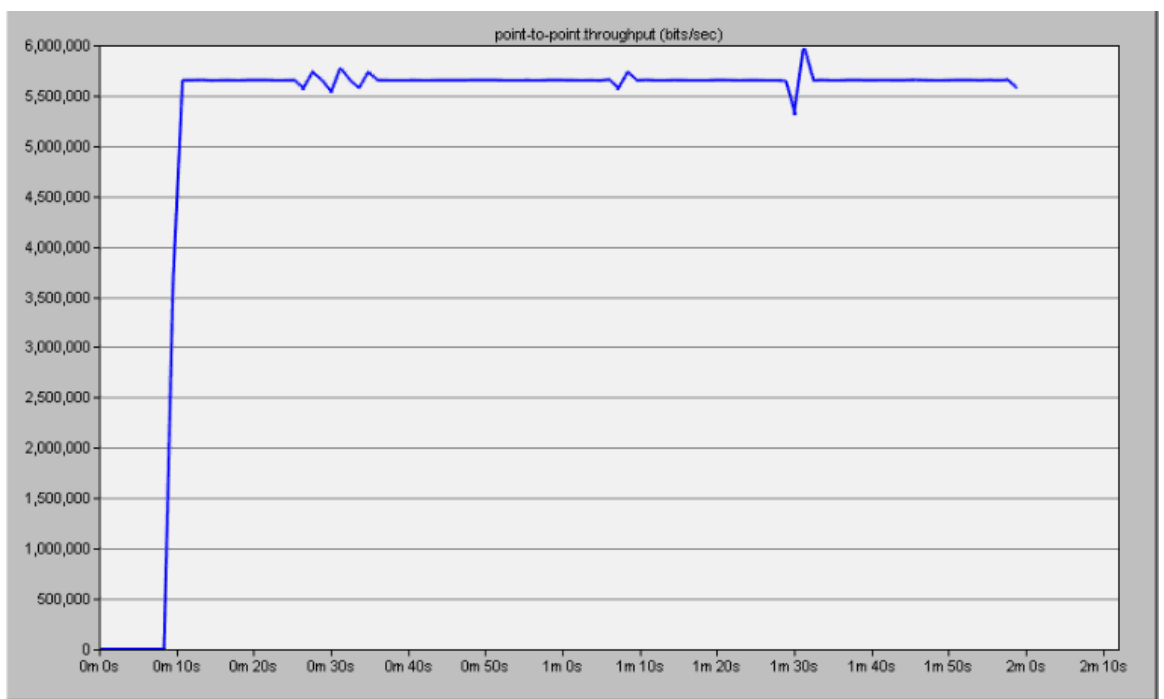

Figure 5. Flow throughput of the message. 
Therefore, it is zero. The Gigabit broadband of the Switch is capable of meeting the requirement of flow for transmission of message.

\subsection{Flow Analysis during the Substation Accident}

During the information transmission in a substation, when there is accident to the substation, the fault and the operation information are transmitted in the form of GOOSE message in IEC 61850 Standard, and the data in SV message is transmitted simultaneously.

Figure 7 demonstrates the fault GOOSE message information. It can be seen that the average delay of the GOOSE subnet network is between 300 to $400 \mu \mathrm{s}$. For the point-to-point data exchange, the data should pass through three intelligent equipment and the Switch. Then the network point-to-point delay of GOOSE message is $430 \times 3+430=1.73 \mathrm{~ms}$. It can be concluded from the simulation that GOOSE message can meet the requirement of the Smart substation.

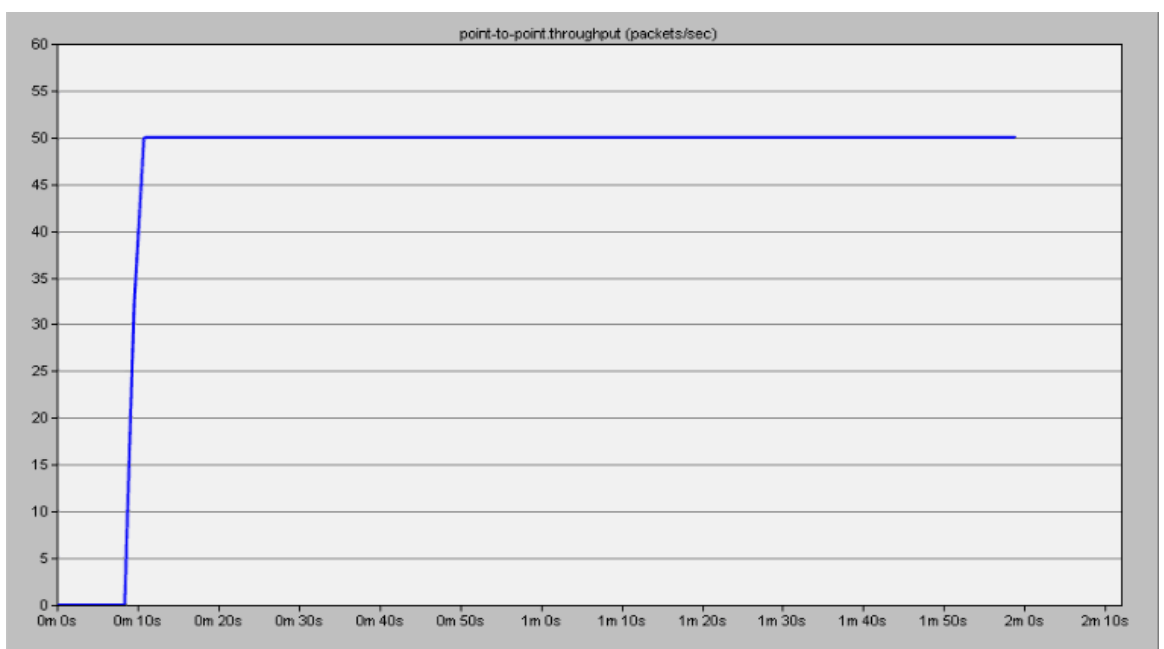

Figure 6. Recording the number of the packets per second.

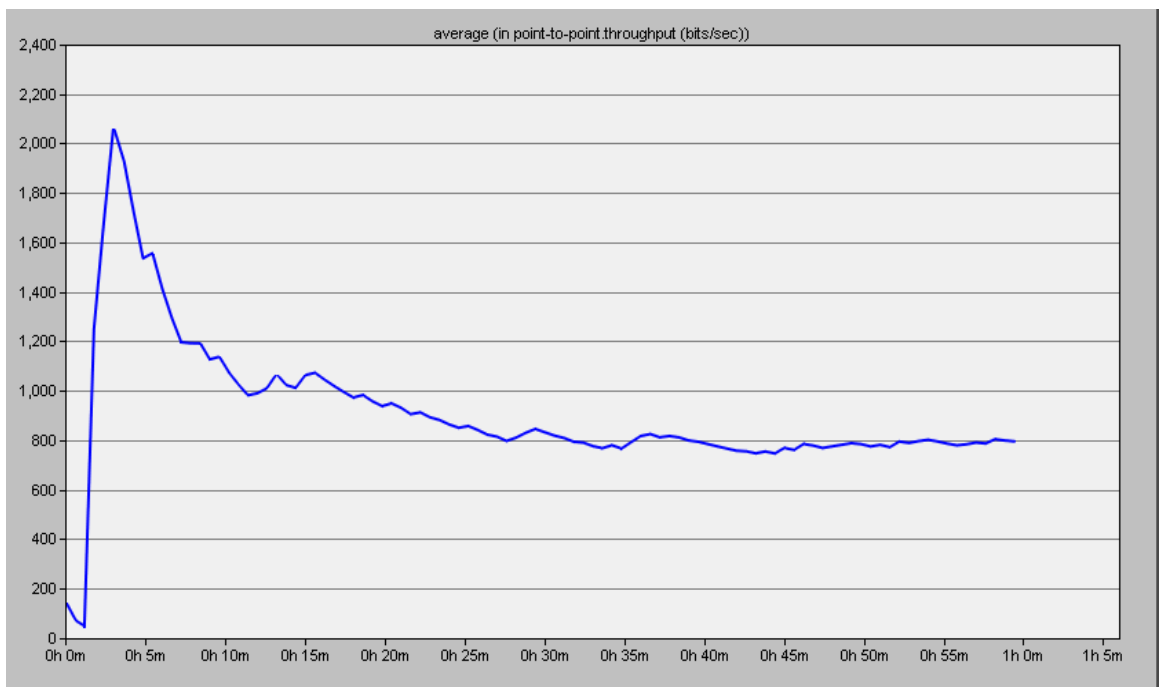

Figure 7. The average delay of GOOSE subnet. 
Figure 8 shows the testing of transmitting and receiving message at the terminal of the Switch. It can be seen from the chart that no packet is lost during the transmission of the message. It is shown in Figure 9 that the maximum point-to-point delay of tip node 1 at the terminal of the Switch is $6 \mu s$. When the message is transmitted, the last delay is stabilized at about $3.5 \mu \mathrm{s}$. The model in this paper simulates the interval Switch in the $220 \mathrm{kV}$ process level. Total 16 MByte terminals and 6 Gigabit terminals are designed. Therefore, the delay of the Switch at the bottom level can be completely neglected.

\section{Conclusion}

Based on the $220 \mathrm{kV}$ integrated automatic substation, the advantages of double star topology are analyzed. It is proposed to divide different VLANs by the Tag

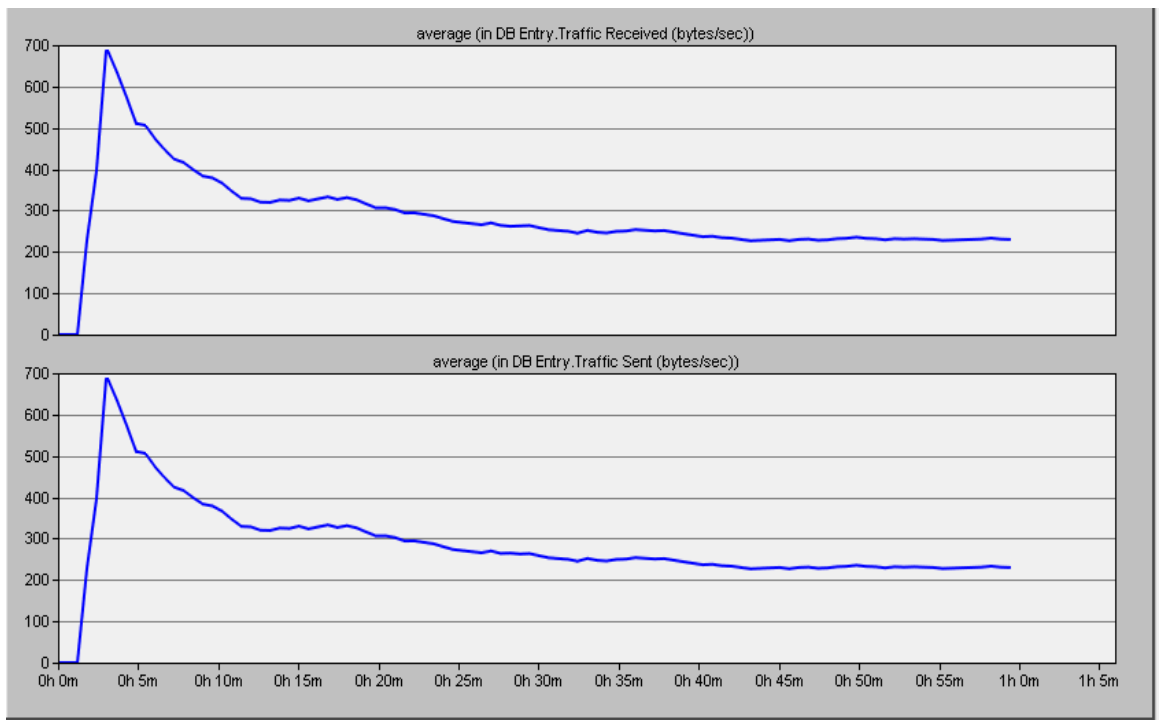

Figure 8. Data exchange diagram at the switch terminal.

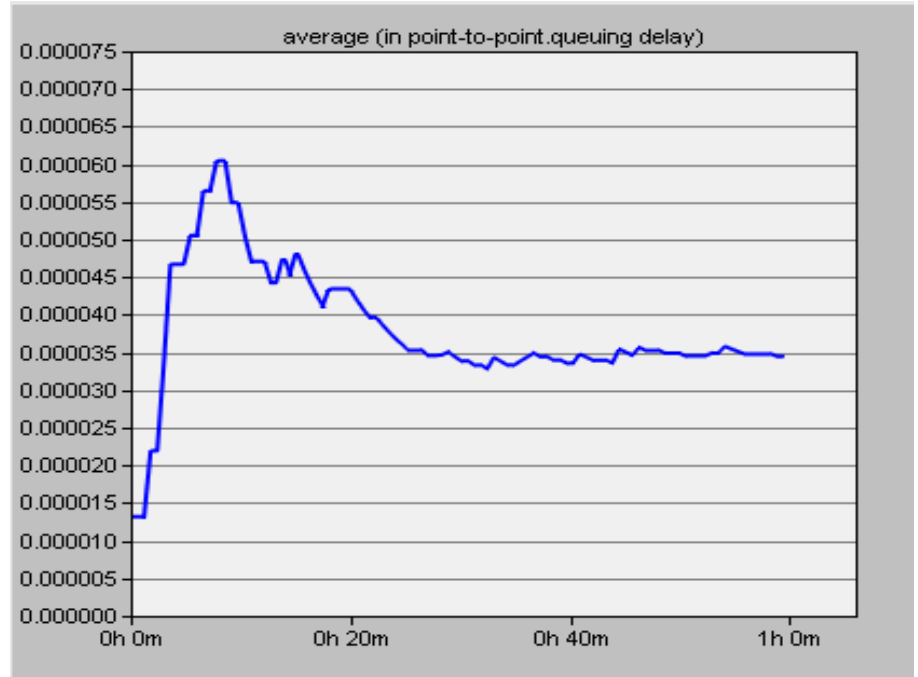

Figure 9. Point-to-point queuing delay at the terminal of the interval switch in the process level. 
VLAN technology based on VID, which enhances the communication reliability inside the substation and realizes the control to the network flow. The MAC address in the network is configured. OPNET simulation software is used to analyze and verify the simulation of double star topology. The result shows that both the delay and the flow bandwidth meet the operation standards of a practical substation. Compared with the normal single star network, the reliability of the double star network is significantly enhanced and the effectiveness is evidently improved.

\section{Conflicts of Interest}

The authors declare no conflicts of interest regarding the publication of this paper.

\section{References}

[1] Li, F., Xie, J., Lan, J.B., Xia, Y.Y. and Qian, G.M. (2012) Prospect and Discussion of Relay System Configuration for Intelligent Substation. Electric Power Automation Equipment, 32, 122-126.

[2] Huang, Y.Z. (2013) Smart Substation Is the Further Objective of SAS. Power System Protection and Control, 41, 45-48.

[3] Zhang, W., Li, Y.P., Kang, F., Chen, Q.X. and Ye, P.Y. (2016) Arc Protection System in Ring Network Distribution Mode for the Intelligent Substation. Huadian Technology, 45, 11-14.

[4] Liu, W., Wang, H.Z. and Zhang, Y.X. (2014) Analysis to the Network Message Characteristics in the Process Level of the Intelligent Substation and Study on the Communication Configuration. Protection and Control of Electrical Power System, 44, 110-115.

[5] He, Q.S., Zeng, L.K., Ou, Q.H., Jiang, L.H. and Wang, X.Y. (2014) Business Sectional Flow Analysis Method for Distribution Communication Network. Automation of Electric Power System, 23, 91-95.

[6] Cai, J.R. and Zheng, Y.C. (2016) A Survey of Research on Secondary Device Condition Monitoring in Smart Substation. Protection and Control of Electrical Power System, 44, 148-153.

[7] Zhang, X.J., Liu, Y. and Yu, H.W. (2015) Overload Isolation and Control Strategy of Smart Substation MMS, GOOSE, and SV Three-in-One Communication Network. Protection and Control of Electrical Power System, 43, 120-126.

[8] Huang, Z.Y., Duan, X.Y., Zou, Y. and Zhang, C.P. (2008) Digital Interface of Electronic Transformer Based on VLAN Technology. Transactions of China Electrotechnical Society, 23, 36-40.

[9] Ding, L., Wang, X.R. and Tong, X.Y. (2008) Sampled Value Transmission Simulation Based on IEC 61850 of EPOCHS Platform. Automation of Electrical System, No. 20, 67-72.

[10] Zhan, R.R., Li, Y.J., Zhang, X.L, Zhan, Z.H., Yu, Y., et al. (2014) Research on Testing Technology of Relay Protection for Intelligent Substations. Electricity, No. 5, 38-43.

[11] Huang, M.H., Shao, X.C., Zhang, C., Wang, H.Z., Li, Y.Q., et al. (2013) Modeling and Simulation of Relay Protection of the Intelligent Substation Based on OPNET. Electric Power Automation Equipment, No. 5, 144-149. 